\title{
SIMULTANEOUS EVALUATION OF COMMUNICATION SKILLS BY STANDARDIZED PATIENTS AND MEDICAL EVALUATORS
}

\author{
Miguel A. Fernández-Villacañas, Matilde Moreno-Cascales, Sergio Alemán-Belando, \\ Manuel Matías-Sánchez, Diego Flores-Funes, Carmen Botella, Joaquín García-Estañ * \\ Centro de Estudios en Educación Médica, Facultad de Medicina, Universidad de Murcia \\ (Spain)
}

Corresponding author: Joaquín García-Estañ, Centro de Estudios en Educación Médica, Facultad de Medicina, Campus de El Palmar, 30120 Murcia, Spain. Phone: 34868-884880; Fax: 34-868-884150; E-mail: jgestan@um.es

Running title: Doctors and patients communication skills evaluation

\begin{abstract}
Background: The present study analyzes the evaluation of communication skills by standardized patients (SPs) and medical evaluators (Es) in an OSCE setting.

Methods: The OSCE involved 189 sixth-year medical students, as well as 34 SPs and 63 Es. Communications skills were evaluated in 8 stations, simultaneously by SPs and Es. The SPs were actors who had been trained in the clinical case and who acted in accordance with a standardized script in a simulated clinical situation. The evaluators, also standardized, were Resident Doctors or staff Doctors from the Hospital Services involved.

Results: The global scores awarded to students for communication skills were very similar in both groups, although the score awarded by Es was significantly higher, and a direct relationship was also observed between the mean scores awarded by both groups. Evaluators awarded significantly higher scores than SPs in 7 out of the 10 items on the checklist. Female medical students also scored significantly higher than their male counterparts in many items, including external appearance, listening, cordiality, optimism, interest, expression and empathy.

Conclusions: Our data indicate that SPs and Es evaluated communication skills in a similar manner in an OSCE setting, a finding which suggests that health-related professionals can be used as an alternative to SPs, thus helping to lower economic costs. Our study also confirms a gender difference (in favor of women) in the evaluation of communications skills by both groups.
\end{abstract}

Keywords: communication skills, standardized patients, gender, checklist, competence assessment, OSCE.

\section{Background}

Objective Structured Clinical Examination (OSCE) is a form of performancebased testing used to measure clinical competence, mostly among health science students. Communication skills are one of the most important competences evaluated in 
an OSCE, since they are essential for the proper preparation of the clinical history and physical examination, as well as helping to ensure humane treatment and the best quality care. In addition to patient care, however, communication skills are also essential for teamwork and relationships with other colleagues and professionals, all of which should result in improved healthcare.

This type of evaluation has traditionally been carried out by non health professionals, generally people recruited as actors who represent a clinical case or scenario mimicking a real patient. It seems logical, therefore, that they be the ones required to evaluate the behavior of the person treating them. The correct way to perform this task is through patient standardization, a process in which all simulated patients are trained to faithfully represent their clinical case, as well as to evaluate clinical communication competence in a fair and objective manner. People thus trained are known as standardized patients (SPs). In this case, SPs are trained to evaluate students' skills based on a checklist of items for each station. They play through the interaction with the student, and then score them on the basis of their observations (1-3).

The advantages and disadvantages of SPs have been reviewed elsewhere, but there is general agreement regarding the fact that they reduce inter-rater variability in scoring students' performance (4). However, one major issue is that using people outside the institution is expensive and greatly increases the overall cost of the OSCE. Our aim with this study was therefore to determine whether or not any differences could be observed between the evaluation of communication skills by a standardized patient (SP) or by a medical evaluator (E). The literature in this area of medical education is limited and conflicting. Some studies have suggested that SP examiners are at least as reliable and "accurate" as physician examiners in evaluating student performance, while others have found SP raters to be inferior (4-6). Our second aim was to assess the possible existence of gender differences in the communication skills evaluation process, an issue which has already been explored in some depth (4-5).

\section{Methods}

The OSCE test was conducted at the University of Murcia School of Medicine in June 2016, with 189 sixth-year undergraduate medical students. It consisted of a circuit of 20 stations with a time of 8 minutes per station and 2 minutes rest time between stations. The test was completed in 3 simultaneous runs, each comprising 20 students, with a total of 5 turns. Following the recommendations of the Spanish National Association of Deans of Medicine (CNDFME) (7), the clinical competence areas evaluated during the test were: 1) anamnesis (history taking), 2) physical examination, 3) technical skills and procedures, 4) communication skills, 5) clinical judgment, diagnostic and therapeutic management, 6) prevention and promotion of health, 7) interprofessional relations and 8) ethical-legal aspects and professionalism. The stations consisted of standardized patients, mannequin/procedures, a structured oral examination (with or without mannequin) and clinical reports. The present study was conducted exclusively at the 8 stations in which competence \# 4 (communication skills) was evaluated, namely Cardiology, Hematology, Internal Medicine, Legal Medicine, Neurology, Oncology, Otorhinolaryngology and Family Medicine. These stations used standardized patients (SPs), i.e. non medical actors who had been trained in the clinical case and who acted in accordance with a standardized script in a simulated clinical situation. Actors were recruited from the local actors' association. An evaluator (E) was also present at each of the 8 stations to assess the corresponding medical components. 
These Es were Resident (in specialization training) Doctors or staff Doctors from the Hospital Services involved. Both SPs and Es were previously standardized in sessions specially designed for this purpose. First, they attended several (2-3) 1-2 hour sessions in order to learn about the clinical case and standardize their role or evaluation, respectively. These sessions were led by the professor responsible for the case design. Next, another session was run by the OSCE coordinators to perform the standardization. During this session, a total of 14 simulated students, all of them first-year residents, were used as OSCE students.

Table 1. Communication checklist.

\begin{tabular}{|l|}
\hline External appearance: Careful appearance, good hygiene, correct body posture \\
\hline Listening: Listens properly, does not interrupt, is attentive, watches while talking \\
\hline Cordiality: Make pleasant first contact, smiles \\
\hline Respect: At no time criticizes or makes pejorative judgments \\
\hline Tranquility: Stays calm, emotionally controlled \\
\hline Optimism: Sees the positive aspects of situations, tries to encourage the patient \\
\hline $\begin{array}{l}\text { Contact: Any physical contact during physical examination or greeting is careful } \\
\text { and kind }\end{array}$ \\
\hline Interest: Is interested in opinions, beliefs, values, concerns and emotions \\
\hline Expression: Expresses themselves clearly at all times \\
\hline $\begin{array}{l}\text { Empathy: When faced with intense patient emotions (pain, anxiety, joy), } \\
\text { participates and sympathizes or tries to understand them in order to help the patient } \\
\text { cope with them }\end{array}$ \\
\hline
\end{tabular}

Finally, on the day of the OSCE, communication skills were evaluated simultaneously by both the SPs and the Es, once the students had left the station, with all participants having 2 minutes to complete the checklist (Table 1). Both SPs and Es were instructed to score independently. The checklist used was a Likert-type rubric comprising 10 items, and is the one employed by all Schools of Medicine in Spain, as proposed by the CNDFME in 2012 (7). It was developed on the basis of the previous version used and validated in our country (8). Each item was scored on a 5-point scale with levels ranging from "very poor", "poor", "average", "good" and "excellent". The encounters were neither audiotaped nor videotaped. SPs (but not Es) received a $€ 50$ honorarium per run. A total of 34 SPs and 63 Es were used.

\section{Statistics}

Since the Kolmogorov-Smirnov test revealed a normal distribution of the sample data, a t-Student test was performed to compare the means (both total and separate) in each of the 10 items evaluated. The unpaired t test was used to evaluate gender differences. A difference between groups was considered significant at a level of $\mathrm{P}<0.05$.

\section{Results}

The test involved 189 sixth-year undergraduate medical students, with a mean age of 23 years and a range of between 22 and 28 . The majority were women (109, $57.7 \%$; 80 men, $42.3 \%$ ). 


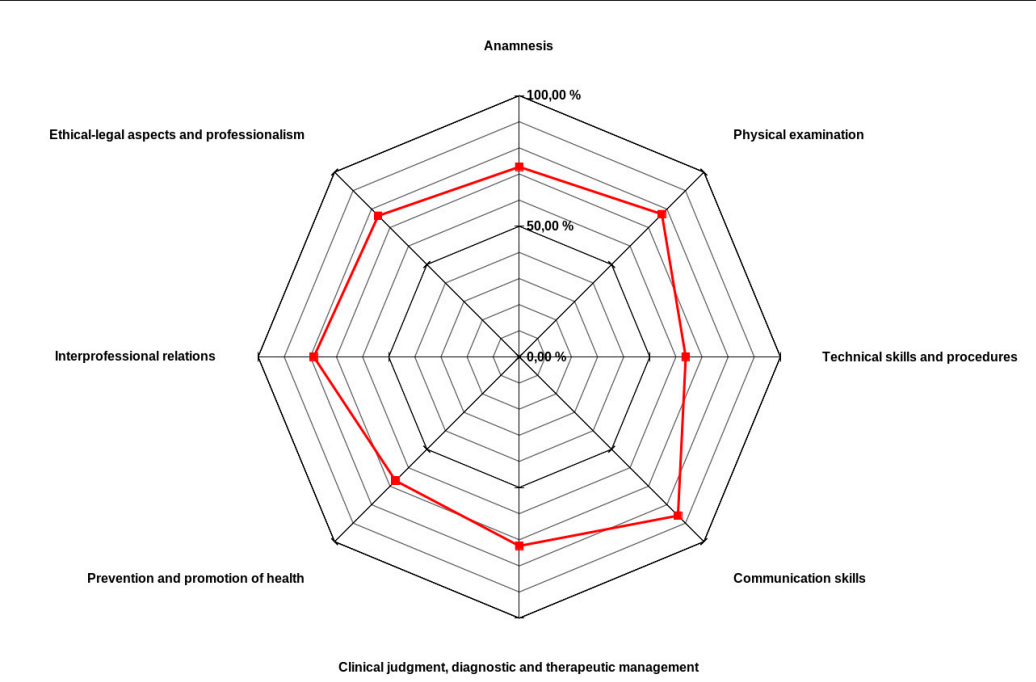

Figure 1. Global results of the OSCE, organized by competences.
Figure 1 shows a representation of the global scores obtained by the students in each of the analyzed competences. The mean overall score obtained by students (with the SP evaluation value) was 73.23 points +4.62 (women: $73.73 \pm 4.80$ and men: $72.53 \pm 4.20$ ), out of a possible maximum of 100 . In the case of

communication skills, which obtained the highest value of all in both SP and E evaluations, the global scores were very similar in both groups, although the $\mathrm{E}$ evaluation score was significantly higher (Table 2). These differences between SP and E evaluation scores were also observed for both men and women in the items Respect and Contact. However, women were evaluated significantly higher for the items Optimism, Interest and Empathy, whereas men scored higher for Listening and Contact (Table 2). A direct relationship was also observed between the scores awarded by SPs and Es (Figure 2). The correlation coefficient was 0.81 .

As regards gender, women consistently scored higher than men, with the difference being significant in

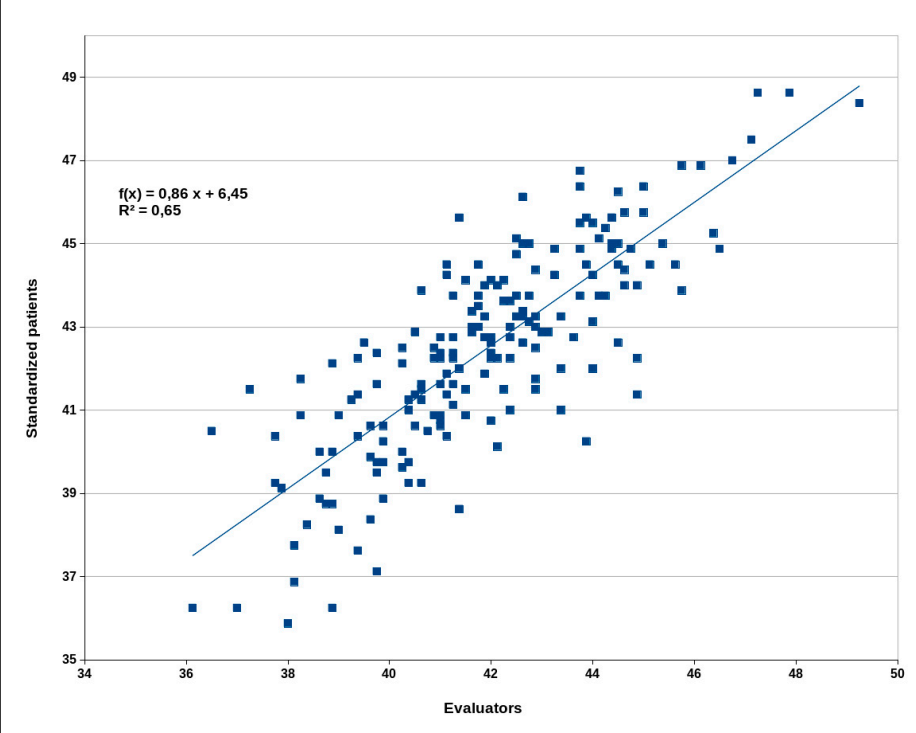
11 (out of 20) of these Figure 2. Dispersion diagram reflecting the relationship between comparisons, including external the communications skills' evaluations of standardized patients appearance, listening, and evaluators. cordiality, optimism, interest, expression and empathy.

\section{Discussion}

The primary aim of the present study was to analyze the results of the communication skills evaluation performed by SPs and Es during an OSCE of medical students. Despite some interesting differences which will be discussed below, the results reveal a very good general correlation between the evaluations conducted by the two groups (SP and E), thus suggesting that they could be carried out indistinctly. Although 
there is a significant overall difference between them, this may be due to the large sample size (almost 190 medical students). Thus, differences between 41.9 and 42.5 points (Table 2) have very little educational meaning. Similar data have also been reported by other studies $(5,9-13)$, although most of these analyzed the role of SPs as evaluators of clinical matters.

Table 2. Absolute values awarded in the assessment of communication by standardized patients (SP) and evaluators $(\mathrm{E}) .{ }^{*}, \mathrm{p}<0.05$ between $\mathrm{SP}$ and $\mathrm{E} ;+, \mathrm{p}<0.05$ between Women and Men.

\begin{tabular}{|c|c|c|c|c|}
\hline & & GLOBAL (\%) & WOMEN (\%) & MEN (\%) \\
\hline \multirow[t]{2}{*}{ Total score } & SP & $41.9 \pm 2.31$ & $42.29 \pm 2.12+$ & $41.36 \pm 2.47$ \\
\hline & $\mathbf{E}$ & $42.47 \pm 2.45 *$ & $42.85 \pm 2.35 *+$ & $41.94 \pm 2.51 *$ \\
\hline \multirow[t]{2}{*}{ External appearance } & SP & $4.66 \pm 0.21$ & $4.69 \pm 0.15+$ & $4.61 \pm 0.26$ \\
\hline & $\mathbf{E}$ & $4.64 \pm 0.27$ & $4.69 \pm 0.23+$ & $4.57 \pm 0.31$ \\
\hline \multirow[t]{2}{*}{ Listening } & SP & $4.33 \pm 0.30$ & $4.39 \pm 0.26+$ & $4.25 \pm 0.34$ \\
\hline & $\mathbf{E}$ & $4.39 \pm 0.25 *$ & $4.42 \pm 0.25$ & $4.35 \pm 0.25 *$ \\
\hline \multirow[t]{2}{*}{ Cordiality } & SP & $4.39 \pm 0.31$ & $4.43 \pm 0.30+$ & $4.33 \pm 0.31$ \\
\hline & $\mathbf{E}$ & $4.40 \pm 0.32$ & $4.43 \pm 0.31$ & $4.36 \pm 0.33$ \\
\hline \multirow[t]{2}{*}{ Respect } & SP & $4.48 \pm 0.24$ & $4.51 \pm 0.25$ & $4.45 \pm 0.22$ \\
\hline & $\mathbf{E}$ & $4.64 \pm 0.23 *$ & $4.64 \pm 0.22 *$ & $4.61 \pm 0.24 *$ \\
\hline \multirow[t]{2}{*}{ Tranquility } & SP & $4.13 \pm 0.38$ & $4.17 \pm 0.38$ & $4.07 \pm 0.38$ \\
\hline & $\mathbf{E}$ & $4.18 \pm 0.34 *$ & $4.20 \pm 0.34$ & $4.13 \pm 0.35$ \\
\hline \multirow[t]{2}{*}{ Optimism } & SP & $3.90 \pm 0.38$ & $3.94 \pm 0.36$ & $3.85 \pm 0.39$ \\
\hline & $\mathbf{E}$ & $3.96 \pm 0.36 *$ & $4.01 \pm 0.33 *+$ & $3.88 \pm 0.39$ \\
\hline \multirow[t]{2}{*}{ Contact } & SP & $4.08 \pm 0.40$ & $4.12 \pm 0.41$ & $4.03 \pm 0.38$ \\
\hline & $\mathbf{E}$ & $4.17 \pm 0.40$ * & $4.21 \pm 0.39 *$ & $4.12 \pm 0.42 *$ \\
\hline \multirow[t]{2}{*}{ Interest } & SP & $3.83 \pm 0.35$ & $3.88 \pm 0.33+$ & $3.76 \pm 0.35$ \\
\hline & $\mathbf{E}$ & $3.90 \pm 0.35 *$ & $3.95 \pm 0.34 *+$ & $3.83 \pm 0.34$ \\
\hline \multirow[t]{2}{*}{ Expression } & SP & $4.20 \pm 0.31$ & $4.24 \pm 0.30+$ & $4.15 \pm 0.31$ \\
\hline & $\mathbf{E}$ & $4.22 \pm 0.35$ & $4.24 \pm 0.35$ & $4.18 \pm 0.33$ \\
\hline \multirow[t]{2}{*}{ Empathy } & SP & SP & $3.90 \pm 0.33$ & $3.85 \pm 0.37$ \\
\hline & $\mathbf{E}$ & $3.97 \pm 0.36^{*}$ & $4.03 \pm 0.36^{*}+$ & $3.88 \pm 0.34$ \\
\hline
\end{tabular}

Although it has been suggested that lay examiners tend to be more lenient than physicians $(10,13-14)$, in our data, most Es awarded higher scores than SPs in all 
communication skills items but one (external appearance). This finding is partially consistent with that reported previously in another study (15). It is possible that some of the Es may have known the students previously, having been their teachers in class or their tutors in the hospital. Thus, a tendency towards awarding higher scores to future colleagues cannot be ruled out. Also, the situation of SPs, who act as patients, may be more demanding, thus prompting them to evaluate more harshly and demand better treatment, as indeed any real patient would do. These differences may also be dependent on the skills being rated, since it has been shown that while SPs perform better for communication skills (6), the judgments involved in assessing physical exam skills, history taking or clinical management may be more difficult for them to make, even with training. Such considerations should be taken into account, along with availability and cost trade-offs, when deciding which types of raters are effective for which kinds of stations/skills.

Significantly different responses were observed in some of the individual items on the checklist in accordance with student gender. Thus, women were evaluated significantly better for the items Optimism, Interest and Empathy, whereas men were evaluated better for Listening and Contact. A similar result was obtained by Graf et al. (5) who reported a significant gender difference in favor of female students in the empathy dimension, along with more positive statements.

In conclusion, SPs and Es evaluated communication skills similarly in an OSCE setting, suggesting that health-related professionals can be used as an alternative to SPs, thus helping to lower economic costs. Our study also found a gender difference, in favor of women, in the evaluation of communications skills by both groups, thus suggesting that women demonstrate superior skills to men, which confirms recent studies (5).

\section{Conclusion}

Communication skills were very similarly evaluated by standardized patients and medical evaluators, although the score awarded by Es was significantly higher, and a direct relationship was also observed between the mean scores awarded by both groups. Female medical students scored significantly higher than their male counterparts in many communication skills items, including external appearance, listening, cordiality, optimism, interest, expression and empathy. Our finding suggests that health-related professionals can be used as an alternative to standardized patients, thus helping to lower economic costs of an OSCE. Our study also confirms a gender bias (in favor of women) in the evaluation of communications skills.

\section{List of abbrevations}

OSCE, Objective structured clinical examination; SPs, standardized patients; Es, evaluators; CNDFME, Spanish National Association of Deans of Medicine;

\section{Declarations}

- Consent for publication: All participants verbally agreed to participate in the OSCE test and approved the publication of results of the test.

- Availability of data and material: the dataset is available from the corresponding author on reasonable request.

- Competing interests: The authors have no declarations of interest to report.

- Funding: none 
- Authors' contributions: All authors participated in the study concept and experimental design. MAFV, MMC, CB and JGE performed standardization of SPs and Es. SAB, MMS and DFF were responsible for the evaluated stations, collection of forms and spreadsheet coding. MMS and JGE performed the statistical analysis. MMS, CB and JGE drafted the manuscript. All authors read and approved the final manuscript.

- Acknowledgments: we are grateful for all the actors, professors and students who participated in the OSCE.

- Authors' information :

- Dr. Fernández-Villacañas is Professor of Anatomy at the Medical School of the University of Murcia (mafvm@um.es).

- Dr. Moreno-Cascales is also a Professor of Anatomy at the Medical School of the University of Murcia. She currently is the Director of the Center for the Study of Medical Education of the University of Murcia (

- Dr. Alemán-Belando is $4^{\text {th }}$ year Resident of Internal Medicine at the Hospital Morales Meseguer, in Murcia (sergio.aleman.belando@gmail.com).

- Dr. Matías-Sánchez is a $4^{\text {th }}$ year Resident of Ear, Nose and Throat at the Hospital Virgen de la Arrixaca in Murcia (manuams21@gmail.com).

- Dr. Flores-Funes is $4^{\text {th }}$ year Resident of Surgery at the Hospital Universitario Morales Meseguer, in Murcia (diego.ff90@gmail.com).

- Dr. Botella is Immunologist and Teaching Technician at the Hospital Virgen de la Arrixaca in Murcia (carmen.botellam@gmail.com).

- Dr. García-Estañ is Professor of Physiology at the Medical School of the University of Murcia and he is currently the Secretary of the Center for the Study of Medical Education of the University of Murcia (jgestan@um.es).

\section{References.}

1. Barrows HS. An overview of the uses of standardized patients for teaching and evaluating clinical skills. Acad Med. 1993; 68(6): 443-451.

2. Chong L, Taylor S, Haywood M, Adelstein BA, Shulruf B. Examiner seniority and experience are associated with bias when scoring communication, but not examination, skills in objective structured clinical examinations in Australia. J Educ Eval Health Prof. 2018; 15(0):17-0. doi: 10.3352/jeehp.2018.15.17.

3. Schleicher I, Leitner K, Juenger J, Moeltner A, Ruesseler M, Bender B, Sterz J, Schuettler KF, Koenig S, Kreuder JG. Examiner effect on the objective structured clinical exam: a study at five medical schools. BMC Med Educ. 2017; 17:71. doi:10.1186/s12909-017-0908-1.

4. Setyonugroho W, Kennedy KM, Kropmans TJ. Reliability and validity of OSCE checklists used to assess the communication skills of undergraduate medical students: A systematic review. Patient Educ Couns. 2015; 98(12): 1482-1491. doi: 10.1016/j.pec.2015.06.004

5. Graf J, Smolka R, Simoes E, Zipfel S, Junne F, Holderried F, Wosnik A, Doherty AM, Menzel K, Herrmann-Werner A. Communication skills of medical students during the OSCE: Gender-specific differences in a longitudinal trend study. BMC Med Educ. 2017; 17(1): 75. doi: 10.1186/s12909-017-0913-4. 
6. Swanson DB, van der Vleuten CPM. Assessment of Clinical Skills With Standardized Patients: State of the Art Revisited. Teach Learn Med. 2013; 25(S1), S17-S25. doi: 10.1080/10401334.2013.842916.

7. García-Estañ J. Prueba Nacional de Evaluación de Competencias Clínicas de la Conferencia Nacional de Decanos de Facultades de Medicina de España. FEM 2013; 16 (Supl 3): S59-S62.

8. Kronfly E, Ricarte JI, Juncosa S, Martínez-Carretero JM. Evaluation of the clinical competence of Catalonian medicine schools 1994-2006. Evolution of examination formats until the objective and structured clinical evaluation (ECOE). Med Clin. 2007; 129(20): 777-784.

9. Makkuchi A, Takemoto Y, Fukumoto K, Tochino Y, Morimura M, Shuto T. Concurrence and differences between Faculty staff and Standardized patients in the assessment of Medical Students in the postclinical clerkship objective structured clinical examination. AMEE Abstract Book, 2018, page 89. https://amee.org/getattachment/Conferences/AMEE-2018/Abstracts/AMEE2018-Abstract-Book.pdf

10. Heine N, Garman K, Wallace P, Bartos R, Richards A. An analysis of standardised patient checklist errors and their effect on student scores. Med Educ. 2003; 37: 99-104.

11. Han JJ, Kreiter CD, Park H, Ferguson KJ. An experimental comparison of rater performance on an SP-based clinical skills exam. Teach Learn Med. 2006; 18: 304-309.

12. McLaughlin K, Gregor L, Jones A, Coderre S. Can standardized patients replace physicians as OSCE examiners? BMC Med Educ. 2006; 6: 12. doi: 10.1186/1472-6920-6-12.

13. Park J, Ko J, Kim S, Yoo H. Faculty observer and standardized patient accuracy in recording examinees' behaviors using checklists in the clinical performance examination. Korean J Med Educ. 2009; 21: 287-297.

14. Zanetti M, Keller L, Mazor K, Carlin M, Alper E, Hatem D, Gammon W, Pugnaire M. Using standardized patients to assess professionalism: A generalizability study. Teach Learn Med. 2010; 22: 274-279.

15. Regehr G, Freeman R, Robb A, Missiha N, Heisey R. OSCE performance evaluations made by standardized patients: Comparing checklist and global rating scores. Acad Med. 1999; 74(10 Suppl): S135-S137. 